\title{
Lock-in to Application Service Providers
}

Citation for published version (APA):

Müller, R. J., \& Ott, A. (2001). Lock-in to Application Service Providers. In H.U. Buhl, A. Huther, \& B.

Reitwiesner (Eds.), Information Age Economy (pp. 729-742). Springer. https://doi.org/10.1007/978-3-64257547-1_64

Document status and date:

Published: 01/01/2001

DOI:

10.1007/978-3-642-57547-1_64

Document Version:

Publisher's PDF, also known as Version of record

\section{Please check the document version of this publication:}

- A submitted manuscript is the version of the article upon submission and before peer-review. There can be important differences between the submitted version and the official published version of record.

People interested in the research are advised to contact the author for the final version of the publication, or visit the DOI to the publisher's website.

- The final author version and the galley proof are versions of the publication after peer review.

- The final published version features the final layout of the paper including the volume, issue and page numbers.

Link to publication

\footnotetext{
General rights rights.

- You may freely distribute the URL identifying the publication in the public portal. please follow below link for the End User Agreement:

www.umlib.nl/taverne-license

Take down policy

If you believe that this document breaches copyright please contact us at:

repository@maastrichtuniversity.nl

providing details and we will investigate your claim.
}

Copyright and moral rights for the publications made accessible in the public portal are retained by the authors and/or other copyright owners and it is a condition of accessing publications that users recognise and abide by the legal requirements associated with these

- Users may download and print one copy of any publication from the public portal for the purpose of private study or research.

- You may not further distribute the material or use it for any profit-making activity or commercial gain

If the publication is distributed under the terms of Article $25 \mathrm{fa}$ of the Dutch Copyright Act, indicated by the "Taverne" license above, 


\section{Wirtschaftinformatik \\ Wirtschaftinformatik Proceedings 2001}

Association for Information Systems

Year 2001

\section{Lock-in to Application Service Providers}

Rudolf Müller* Alexander M. Ott ${ }^{\dagger}$

*Universiteit Maastricht, r.muller@ke.unimaas.nl

${ }^{\dagger}$ Universiteit Maastricht, alexander.ott@infonomics.unimaas.nl

This paper is posted at AIS Electronic Library (AISeL).

http://aisel.aisnet.org/wi2001/52 
In: Buhl, Hans Ulrich, u.a. (Hg.) 2001. Information Age Economy; 5. Internationale Tagung Wirtschaftsinformatik 2001. Heidelberg: Physica-Verlag

ISBN: 3-7908-1427-X

(C) Physica-Verlag Heidelberg 2001 


\title{
Lock-in to Application Service Providers
}

\author{
Rudolf Müller, Alexander M. Ott
}

Universiteit Maastricht

\begin{abstract}
Renting software applications from an application service provider is generally assumed to provide significant overall cost savings. Whether these savings benefit the customer or provide high profit margins for the provider is a priori not clear. Lock-in of customers might reduce competition and enable the service provider to charge premium prices. We investigate in this paper the strength of lock-in with application service providers and identify the features in service contracts that can be used to reduce the lock-in.
\end{abstract}

Keywords: Application Service Provider, Software economics, Lock-in

\section{Introduction}

Internet and distributed software architectures provide a new way of using hardand software services [WMMR00]. A thin client programme can be used to access powerful software services running on remote hardware. Application Service Provision is a business model that exploits this new technology. Application Service Providers (ASP) rent to their customers online access to applications. For companies, as well as for private households, the ASP can provide access to a range of applications that would be too expensive for own purchase, installation, and maintenance. For applications that have been used in the classical mode before, [Cher99] expects 30-50\% cost savings by help of the ASP model. [McKi99] claims that ASP is a must in every business's future considerations. In this context Scott McNealy, Sun Microsystem CEO, stated that in "five years from now, if you're a CIO with a head for business, you won't be buying computers anymore. You won't buy software either. You'll rent all your resources from a service provider." (Presswire 12/14/99 in [Wend99]).

The ASP market has been receiving much attention during the last two years. It is already fairly developed in the United States, and expected to grow stronger in Germany [Cab100]. Many market studies have recently been published [Berl01; Boul00; Cab100; Igle01; Well99; Wend99], and customer guidelines for ASP selection have been suggested [Igle01; McKi99]. Customers and providers have a choice of several Internet portals that inform on the topic (e.g., www.asp-consortium.com, www.aspisland.com, www.aspnews.com, www.aspstreet.com, 
www.webharbor.com). Customer information is an important issue since the ASP business has many pitfalls, and not all technical problems have been solved yet. It is nevertheless easy to predict that the ASP model will drastically reduce the average total cost of delivery of products and services that are required to bring an application to the desktop of an employee. At the current moment, ASPs deliver access to virtual intranet, enterprise resource planning, groupware, project and workflow management, and e-business applications. In particular, small and medium sized companies (SME) are targeted, as they would traditionally not be able to host such applications on their own [Boul00; Hurw00; Wend99]. However, customers of ASP services will only benefit to a vast extent from overall cost savings under favourable economic conditions. As in other domains in Information and Communication Technology (ICT) it could well be that the nature of the service creates huge margins for the ASP, whilst leaving the customer with relatively high ICT costs. Early economic analysis of the emerging ASP market seems to be advisable in order to understand how the current and future ASP customers can protect themselves against such a disadvantageous situation.

An ASP service is an information product and underlies therefore the principle features of such a product. There are high first copy costs in setting up the ASP infrastructure. Later these services create very low marginal costs for the provider. Regular maintenance such as monitoring the performance and backups can run fully automatic. Less regular work like upgrades benefit from economies of scale as they can be done once for many customers [Wend99; Cher99]. Under strong competition this would lead to sharp price declines. Therefore, ASP providers have to apply strategies that protect their customer base against competitors.

From a customer perspective one economic issue seems most important to us: the ability of the ASP to lock-in the customer. Lock-in is a core concept in order to analyse markets of information products besides versioning, network externalities and price differentiation [ShVa98]. Lock-in is the main strategy to establish a unique relationship with the customer in order to discourage a switch to other providers. [JMBe00] have found in an analysis of the banking and hairdressing/barber sectors that beyond pure customer satisfaction "switching barriers were important factors having an impact on a customer's decision to remain with a service provider". Lock-in enables premium pricing when contracts have to be extended or when the customer demands complementary products and services.

The analysis of switching costs and lock-in in service contracts is in general not widely developed [JMBe00]. For information products, [ShVa98] have very much laid down the foundation. Recent papers on pricing issues in the ASP market analysed primarily the supplier perspective [MaJa00; TaGü00]. [BCKL99; BhCh00] have analysed pricing strategies for intermediaries in certain types of ASP markets. Our analysis also contributes to the emerging field of software economics [BoSu99; MeSz01]. 
This paper combines economic reasoning with observations from market studies. We utilise our findings from interviews with ASP providers done in the second half of 2000, when the second author was working on an internship at Berlecon Research in Berlin. Berlecon Research published an ASP market report in January 2001 (see www.berlecon.de). It provides a comprehensive overview of the German ASP market, and classifies providers by product groups and industries. Analysis of lock-in in the ASP market is not addressed in the Berlecon report. We thank Berlecon to allow us to exploit their findings from the study for this paper.

We begin this paper with an overview of ASP benefits and risks. In the main part, we analyse lock-in factors in the ASP market. In the last section, we conclude and suggest further research.

\section{ASP Benefits and Risks}

ASP is sometimes considered as a third wave of IT outsourcing. It differs however from classical outsourcing as it focuses more on technology outsourcing than on personnel outsourcing. Outsourcing the ICT department often means that the physical location as well as the ownership of hard- and software remains at the organisation. Only the human resources, and by that the know-how of establishing ICT services for the company, are taken over by a contractor. ASP goes further by drastically reducing ownership of soft- and hardware and by that all accompanying costs. Data storage and processing is not anymore done by own resources but purchased as an online service.

The ASP model has as such several obvious advantages over traditional in-house ICT solutions. From an investment perspective, it changes the way of financing ICT. The traditional model is based on leasing or buying hardware and software licenses, and employing personnel for the management and maintenance of these resources. The ASP model replaces this by a pay-per-use model, or other flexible means of pricing [Cher99; TaGü00]. Many variations of payment are possible: from yearly flat fees, to monthly fees per user, to time-based, or CPU-cycle and memory utilization fees. Whatever is chosen, a company can replace long-term investments in equipment and personnel by regular future payments increasing financial flexibility [Wend99; Igle01]. Furthermore, most traditional ICT investments are sunk costs, with high risk of unprofitable investment due to high speed of innovation.

Similar to component providers in manufacturing, application providers benefit from economies of scale and scope. They can offer the same or similar services to many customers [Wend99; Cher99]. On the hardware level they might use the same servers, back-up systems, and communication infrastructure through customers, employing advanced load-balancing techniques. On the software level, 
licenses of special software, which is only occasionally used [GüMü98], have to be purchased only once, but can be used by many different customers. The costper-use ratio of a license can thus decrease tremendously, and licenses become assets of a larger portfolio where risk management can be applied. Knowledge of installing, upgrading and maintaining a software product is created only once at the ASP, versus through its many users. This extends to costs of selecting and purchasing the software. On the human resource level, user help desks may see higher utilisation than in a single organisation.

Customers in the ASP market can also benefit from network externalities. Large ASPs with many customers are able to provide back-end computing facilities that would not be affordable for the individual customer [Cher99]. The ASP might enable interoperation and data exchange between customers (e.g., in project management, procurement, distribution). Partners in a supply chain may host their ERP systems with the same ASP, which enables the ASP to offer supply chain management. ASP customer communities can exchange knowledge of best usage of certain software applications.

Like in many sectors of the New Economy, we will, despite the general optimism, see many failures of companies. Some of them might not be able to provide necessary service quality, or the pricing strategy might not cover costs. A recent case of failure in the ASP market has been hotoffice [Vagh00]. Furthermore, the ASP model is challenged by improvements in traditional software installation, reducing maintenance costs for in-house ICT departments. Additionally running a company without any ICT department could cause significant problems for daily maintenance of equipment and networks that are still needed, even after most applications have been purchased from an ASP. Success or failure of particular ASP business models is therefore hard to predict, leading to a broad range of growth estimates for the market.

\section{Lock-in to Application Service Providers}

With ICT in general, and software applications in particular, there is the effect of lock-in. Under lock-in, a customer's ability to switch to another product or supplier is restricted. Lock-in destroys by that significantly free competition. Its effect is further amplified, if the product has strong network externalities, as the example of Microsoft shows.

Lock-in occurs when a customer of a product or service intends to switch to another supplier, or to another product by the same supplier. In other words, the customer wants to change or extend the contract by which a particular service is sourced. Lock-in is given when the customer observes costs in addition to the price of the new contract. These costs are called switching-costs and they measure 
lock-in [ShVa98]. The decision to switch has to be based on (discounted) value and price for the new contract and the switching costs. A supplier who can observe switching costs is able to increase the price for continuing the contract, since even a more expensive offer could in total be a better option for the customer than that of a competitor. As an example, consider a supplier RentIt of an office application at the price of $\$ 10,000$ per month. Another supplier LeaseIt might offer the same package at $\$ 5,000$. However, if customers of RentIt have switching-costs of more than $\$ 5,001$ they would still consider it to be the better option to stay.

Only if we can identify switching-costs we will have lock-in. This is a rather constraint view. Indeed, accounting literature has observed in practice that past investments bind the decision making at presence, although these investments are sunk costs [HSSt99]. According to the definition used here, sunk costs cannot cause lock-in. For example, past training in a software application does not create switching costs. However, when a new application requires new training, then this training creates switching costs. Similarly, equipment purchased in the past can only create switching costs if there are disposal costs.

In this chapter, we go through the lock-in factors that were discussed in [ShVa98] and apply them to the ASP market. Since an ASP contract reduces possession of software, hardware and human resources in favour of renting these resources, switching costs in the ASP model are expected to be lower in total than under the traditional model. Nevertheless, we will see that many factors influence the level of remaining switching costs.

We do not provide an empirical analysis, since even in established markets a quantification of lock-in is not an easy task [JMBe00]. Instead, we utilise findings from desk research on the Internet and in international and German ASP, IT and outsourcing related business publications. Furthermore, we make use of abundant guided telephone conversations with managers at ASPs. In selecting the ASPs and the managers, careful consideration was paid to two requirements: the ASPs needed to be actively involved in the German ASP business and the conversation partners were supposed to be responsible for strategic ASP development at the ASP.

The interviews were conducted at Berlecon in the second half of 2000 for other purposes than lock-in determination. Each of these interviews was logged in a written form and lasted, with some exceptions, approximately 30 minutes. Important topics and issues for in-depth knowledge on the market, the ASPs, and their offers were mentioned and discussed. These conversations comprised questions on ASP offers, pricing, contracts, additional services, customisations, partner and distribution structures, ASP and software provider experiences, customer acceptance, operational, tactical and strategic perspectives of the ASP market (in general and in specific) and customer penetration strategies. The findings were summarised in an ASP market study [Berl01]. In the following, we use these findings 
to reason about lock-in in the ASP market - an issue that is not covered by the Berlecon study.

\subsection{Contractual Commitments}

Switching costs occur if a contract is broken before the end of the contract period. Short term contracts, as we observe them in the ASP market, do therefore decrease contractual switching costs. On the other hand, with every new contract to be negotiated, the supplier has the opportunity to exploit other types of lock-in. There is therefore a trade-off between the risk of contractual switching costs because of long-term contracts and the risk of lock-in based price increases because of frequent contract renewals.

It is considered to be one of the disadvantages of the ASP model that the risk for the customer of non-appropriate service is hard to estimate [Igle01]. Even a low probability of failure might cause major damage if all operations of the customer rely on a functioning service. Or, as stated in [Lash00]: "After all, the demise of a company that runs your critical software would be a little like the power company's cutting off your service for good." Non-sufficient service increases thus the probability of facing contractual commitment switching costs. Therefore, the service content has to match the needs, and a service level agreement has to protect the customer against failure of service. If the ASP provider is not able to fulfil the service level agreement, this should be compensated [Boul00]. Strong service level agreements are in many cases hard to get because the ASP itself purchases components of the service from other providers [Wend99]. Either he does not have sufficient service level agreements with them, or he is not able to deduce from these agreements the quality level that he can offer to the customer. It is in general a non-trivial task in operations management to calculate the reliability of a network of services [Schr00]. Consequently, interviews showed that most market agreements cover only services directly under control of the ASP.

Another essential part of a contract is pricing. Pricing influences directly contractual switching costs because the pricing agreement determines the costs of a contract that continues without being used anymore. A regular flat fee pricing has the disadvantage that it is independent of usage. Solely activity based pricing (e.g. page hits, number of users in a month) is preferable from a switching cost perspective. The pricing strategies of German ASPs depend very much on the type of applications. We found that ERP systems are typically based on fixed price levels increasing gradually with the number of users. Groupware suppliers offer typically a large range of pricing models. Very often price depends here on counting operations, memory usage, etc. Content-management systems are mostly priced based on memory usage. In most cases set up costs according to installation and set up time have to be added [Wend99]. 
Contractual commitments create switching costs only if they can be enforced. [ArPo99] distinguish formal and informal enforceable contracts. Informal enforcement in the ASP market is based on the relationship and trust that has to be established. Trust and risk will be discussed in a later section. Also of importance is the bundling of contracts. When several contracts have been made to compose one ASP solution, e.g., one for training, one for hosting, and one for the license, then each of them is a durable purchase relative to the other. This is discussed in the following section.

\subsection{Durable Purchases}

Products and services frequently require the purchase of complementary products and services that are necessary or that increase utility. Under the traditional model, an application licence required complementary software licences (e.g., operating system, databases), trained ICT personnel, and hardware investments. Switching the application, required changes in this configuration, all together creating durable purchase switching costs [MeSz01]. Most of these durable purchases do not exist in an ASP relationship, or are part of the service. Therefore, durable purchase switching costs are lower under the ASP model than under traditional ICT.

Durable purchases in the ASP market exist on the network infrastructure level and on the organizational level. On the infrastructure level, ASP contracts increase bandwidth and security requirements. Customers might have to invest above their otherwise necessary Internet engagement. On the organisational level, one may have durable purchases in terms of consultancy and training contracts. Furthermore, there are "durable decisions" in those business functions that utilise the ASP. For example, renting a customer relationship management system from an ASP changes marketing and sales. Similarly, e-business applications are durable in the sense that they implement a way of interaction with customers and business partners.

At the point where a company buys for the first time an ASP solution, historical expenses for application complements are sunk, and therefore should not be considered as switching costs (aside from some disposal costs). Contractual commitments with personnel however do count and have to be considered carefully.

Switching costs for durable purchases in the ASP relationship are high when a customer wants to switch back to own hosting. Switching requires then an immediate investment in personnel and equipment. The strategic decision to use ASP services rather than building up or continuing with an own ICT department is therefore a durable decision. 


\subsection{Brand-specific Training}

A software application in an ASP contract underlies similar brand-specific training for users as traditional software applications. When a switch to another ASP or back to own hosting changes the user-interface, new training is required.

Today ASP services run mostly under two models. The first is the Web-client model, where a Web browser implements the GUI by means of HTML and JavaScript, thereby simulating a Windows or MacOS user-interface. Quite often, the Web interface offers only restricted function. For example, does MS Webmail implement only a subset of the contact management function that one gets with MS Outlook. The Web-client model might therefore reduce the range of functions with respect to an in-house solution. The second client model is the remote client model. In this case, the client machine works as a virtual terminal that directly communicates via Internet with an application server, thereby not using the Web protocol. This model is closely related to a technology that has for many years been available in Unix environments. Citrix was the first software vendor, which offered such way of operation for Windows platforms. These two options have an impact on whether an ASP solution requires a change in the user-interface.

Another issue under this lock-in category is heterogeneity of user interfaces. When different ASP applications are used, maybe from different providers, they are likely to use different interfaces. In this case, brand-specific training is more necessary than with the homogeneity of PC user interfaces today, unless a remote client technology is used. In particular, the groupware ASP market is dominated by proprietary solutions. But also several ASPs for ERP, E-business, CMS and Web methods follow this strategy. Note that another risk of proprietary systems is that of missing network effects due to a small installed base, and missing capacity at the ASP to incorporate innovations.

There is a kind of "negative" brand-specific training in ASP usage. The training of application and server maintenance that takes place in an own IT department is missing. A switch back to own hosting can therefore be very difficult, as mentioned already in the section on contractual commitments above.

Finally, an ASP contract does not only establish relationships between users at the customer side and software applications at the provider side, but also personal and corporate relationships between two organisations. The fact that trust is an essential component in an ASP relationship requires strong investments, which need to be renewed with a new provider.

\subsection{Information and Data}

An essential part of an ASP contract is the hosting of data storage. There are only a few applications that do not involve customer specific data to be stored at the 
ASP's. Emerging decision support applications might change the picture by transporting data just-in-time from the client to the server and the results back to the client [BKMü97], but such applications develop only slowly. Data storage at the ASP's requires moving the data when the provider is changed. The extent, to which switching costs will be generated, depends on several factors.

Proprietary formats play again a prominent role. One may argue that relational databases with SQL access are non-proprietary. Nevertheless, the crucial part here is the database scheme. A switch between providers will almost certainly require a conversion of schemes. Document management systems store, for example, quite a large set of meta-data with every document. Migration problems can be further amplified by customisation. Note that even with a free-of-charge ASP provider such switching costs have to be covered at the end of the relationship.

Some developments in ICT over the last years can be assumed to reduce data and information switching costs. One may for example argue that XML based data storage is helpful. But again, XML defines only the tool by which a specific scheme is developed. Migration will still be necessary unless applications use the same XML data type definition.

Switching costs related to data and information storage are as strong in the ASP market as they are in the regular software market. It is therefore advisable to go only for ASP solutions that use non-proprietary applications, which can be contracted from other providers as well. Furthermore, every customisation of the data storage has to be weighed up to the lock-in that it creates.

\subsection{Search Costs}

Search costs are switching costs that have to be spent in order to find an appropriate alternative to the current contractual situation with an ASP. The transparency of the ASP market is currently very limited [Slav00]. Transparency is not in the interest of ASP providers, as for example product differentiation and specialisation help to charge higher prices. For a customer who intends to switch to ASP services or between providers, missing transparency creates however a large barrier. Several factors decrease the transparency.

The term ASP is used for rather different services. Most of the ASP enablers mentioned earlier like to position themselves as an ASP. A search for Application Service Provider with a Web search engine results only in a few real providers. The heterogeneity of contracts is another problem. Pricing, service level agreements, and other attributes differ with every ASP. There is a diversification in service bundles that makes an exact replacement of an existing contract unlikely. The customer needs a lot of information about every particular offer to reduce risks of bad quality. There is so far no certification of ASP providers. So-called test cen- 
tres try to solve this problem but the market of test centres is itself quite heterogeneous.

\subsection{Loyalty Programmes}

Loyalty programmes are not really observable right now. In phone interviews loyalty credits were announced. It was often mentioned that a continuation of the contract could go hand-in-hand with additional free services. Note that under strong lock-in they are not needed, since loyalty can be achieved by balancing pricing carefully with customer lock-in.

\subsection{Trust and Risk}

Using an ASP is generally observed to involve high risk with respect to data privacy at the ASP and data security during transmissions via the Internet. If nevertheless a contract is made, this indicates that a trust relationship between customer and provider could be established. Not only that this might create mental switching costs because of a regret in breaking a trust-relationship (in other words it creates an informal contract). But also the creation of the relationship with a new provider is cumbersome. While the other switching costs may only be observed after a new contract has been made, the efforts in creating a trust relationship have been observed in the past. Therefore, it is easier for the provider to exploit them in negotiations.

\subsection{Supplier Specialisation}

As a final point, we would like to mention switching costs due to supplier specialisation. Quite a few ASPs have specialised themselves on one application. Examples are project management, time tabling, or advertising management. Such specialisation could mean that an ASP customer has no alternative choices to the current ASP relationship. Specialisation is certainly a valuable strategy from a providers point of view due to the information product character of application services. But it can turn out to be a costly disadvantage for the customer.

An alternative for the customer is to choose a one-stop-shopping solution at an ASP mall. Such a marketplace does not only reduce the transaction costs for the customer, but risk can be better distributed in a portfolio of many applications and customers also. Another strength of ASP malls can be to provide interoperation between applications. Therefore, ASP malls are likely to play a strong role in the market. 


\section{Conclusions}

We have seen that contracting with an ASP is very likely to create strong lock-in. This is in part due to characteristics of the service that is contracted. For example, outsourcing to an ASP necessarily involves a strong trust relationship. And issues like proprietary data formats do not disappear when an ASP service instead of own hosting is used. Some lock-in factors can be reduced by a careful contract design. The main findings in this direction have been:

1. A contract that can be broken due to insufficient service levels, that prices only actual usage, and that guarantees support in switching to other providers in terms of data and information movement, reduces lock-in.

2. Dependencies between the ASP contract and complementary contracts have to be designed carefully. Complementary contracts should be reusable after changing the ASP.

3. The application software should be non-proprietary so that the same application can be rented from other ASPs.

4. Customisation of data schemas should be weighed against data and information lock-in.

5. The number of contracts with different ASPs should be low. Service level agreements should be similar to those obtainable from other ASPs.

6. Loyalty programmes are not necessary in a market with a strong lock-in.

7. Advantages of supplier specialisation have to be weighed against risk of dependence from that supplier.

Not all these measurements change the principal problem that the dependence from an ASP is as critical as the dependence from an in-house ICT department. A cost comparison between both options is due to lacking transparency of the ASP market not an easy task. A short-term contract with an ASP to test an ASP relationship is also tricky, as it creates all the switching costs that we analysed in this paper. We believe that the short-term contracts that are offered do not actually fit with the long-term decisions that have to be made by the customer when outsourcing to an ASP.

This paper can only cover a few issues of the strategic relationships in the ASP market. Further research should specifically develop case studies of contracts and service level agreements. Based on our findings so far, we believe that the complexity of contractual relationships in the ICT domain is increased under the ASP model. Nevertheless, the ASP model has the potential to bring more sophisticated applications to the desktop of small and medium sized enterprises, and to increase the number of users of specialised software applications. In order to distribute these benefits between suppliers and customers in a way that gives all parties an 
incentive to participate in the market further research in the economics of the market is required. Besides a discussion of lock-in, research is needed on pricing, versioning, contract management and network externalities, to name just a few.

\section{References}

[ArPo99] Argyres, N. S., Porter Liebeskind, J.: Contractual Commitments, Bargaining Power, and Governance Inseparability: Incorporating History into Transaction Cost Theory. In: The Academy of Management Review 24 (1999) 1, pp. 49-63.

[Ber101] Berlecon Research: ASP: Das IT-Konzept der Zukunft? Der deutsche Markt und seine Herausforderungen. Berlecon Research, January 2001.

[BKMü97] Bhargava, H. K, Krishnan, R., Müller, R.: Electronic Commerce in Decision Technologies: a Business Cycle Analysis. In: International Journal of Electronic Commerce 1 (1997), pp. 109-127.

[BCKL99] Bhargava, H., Choudary, V., Krishnan, R., Lee, K. B.: Analysis of an Intermediary's Strategies in Electronic Markets for Decision Technologies. International Conference on Information Systems, December 1999.

[BhCh00] Bhargava, H. K., Choudhary, V.: Second-Degree Price Discrimination for Information Goods Under Nonlinear Utility Functions. Working paper, Smeal College of Business, Pennsylvania State University 2000.

[BoSu99] Boehme, B. W., Sullivan, K. J.: Software Economics. In: Finkelstein, A. (ed.): The Future of Software Engineering, Special Volume. 22nd International Conference on Software Engineering, ACM press (to appear), http://www.cs.ucl.ac.uk/staff/ A.Finkelstein/fose/fdboehm.pdf, June 2000, as of 2001-02-28.

[Boul00] Boulanger, D.: The Enterprise Application Service Provider Report, 1999-2004. AMR Research, Inc., http://www.amrresearch.com, 2000, as of 2000-09-13.

[Cab100] Cable \& Wireless: Key Issues Within the ASP Market. Cable \& Wireless, www.usa.cwas.net/Collateral/news_room/Market_Background.pdf, 2000, as of 200001-19.

[Cher99] Cherry Tree \& Co.: Application Service Providers, a Spotlight Report. http://www.cherrytreeco.com/current/reports/asp.pdf, 1999, as of 2000-05-15.

[GüMü98] Günther, O., Müller, R.: From GISystems to GIServices: Spatial Computing in the Internet Marketplace. In: Egenhofer, M., Goodchild, M. (eds.): Interoperability in Geographic Information Systems. Taylor \& Francis 1998, pp. 427-442.

[HSSt99] Horngren, C. T., Sundem, G., Stratton, W.: Introduction to Management Accounting. Prentice Hall International, Inc., Upper Saddle River, New Jersey 1999.

[Hurw00] Hurwitz Group, Inc.: Hurwitz Report - How Small and Midsize Businesses Can Turn the Internet into a Private Network for Competitive Advantage. Hurwitz Group, Inc., June 2000. 
[Igle01] Igler, M.: Mieten statt kaufen - Abrufbare IT-Leistung. In: ASP Leitfaden. Lünendonk, http://www.tds.de, as of 2001-02-28.

[JMBe00] Jones, M. J., Mothersbaugh, D. L., Beatty, S. E.: Switching Barriers and Repurchase Intentions in Services. In: Journal of Retailing 76 (2000) 2, pp. 259-74.

[Lash00] Lashinsky, A.: Don't Get Bitten by the ASPs. In: Fortune, http://www.proquest.umi.com/pqdweb?TS=971189010\&Did=000000060743753\&Mtd $=1 \&$ Fmt $=3 \&$ Sid $=6 \& I d x=1 \&$ Deli $=1 \&$ RQT $=309 \& D t p=1,2000-10-02$, as of 2000-1010 .

[MaJa00] Marchand, N., Jacobsen, H.-A.. An Economic Model to Study Dependencies Between Software Application Vendors and Application Service Providers. In: 3rd Berlin Internet Economics Workshop, as of 2000-05-26.

[McKi99] McKie, S.: Outsourcing With ASPs in the Internet Age. http://www.businessfinancemag.com/archives/appfiles/Article.cfm?IssueIS=304\&ArticleID=13186, as of 2000-10-14.

[MeSz01] Messerschmitt, D. G., Szyperski, C.: Industrial and Economic Properties of Software: Technology, Processes, and Value. In: University of California at Berkeley Computer Science Division Technical Report UCB//CSD-01-1130 and Microsoft Corporation Technical Report MSR-TR-2001-11, http://divine.eecs.berkeley.edu/ messer// PAPERS/01/Software -econ/, 2001-01-18, as of 22.01.2001.

[Schr00] Schröder, R. G.: Operations Management - Contemporary Concepts and Cases. Irwin McGraw-Hill 2000.

[ShVa98] Shapiro, C., Varian, H. R.: Information Rules - A Strategic Guide to the Network Economy. Harvard Business School Press, Boston, Massachusetts 1998.

[Slav00] Slavid, D.: There Must Be a Better Channel Model! http://www.aspnews. com/analysis/analyst_cols/article/0.2350.4431_429861.00.html, as of 2000-09-29.

[TaGü00] Tamm, G., Günther, O.: Electronic Commerce Business Concepts for Server Based Computing. In: Proceedings of ITS 2000, http://www.its2000.org.ar/conference/ tamm_gunther.pdf, as of 2001-01-20.

[Well99] Weller, T. C.: Application Hosting Market. http://www.leggmason.com/pdf/tweller12_30_99.pdf, as of 2001-02-28.

[Wend99] Wendland, R.: Application Service Providers. Durlacher, http://www.durlacher.com, as of 2000-05-15.

[WMMR00] Westhead, K., Mortenson, C., Moore, J., Rice, W. A.: New Economy -Forget the Web, Make Way for the Grid. Dt. Bank Global Technology Team, http://www.nmm.com/documents/DBNewEconomy_report.pdf, as of 2001-05-15.

[Vagh00] Vaughan-Nichols, S. J.: Hotoffice Goes Ice Cold. In: Techweb, http://www.zdnet.com/sp/stories/news/0,4538,2663245,00.html, as of 2000-01-23. 